\title{
Universiteit
}

Leiden

The Netherlands

\section{Direct determination of a molecular torsional angle in the membrane protein rhodopsin by solid-state NMR}

Feng, X.; Verdegem, P.J.E.; Lee, Y.K.; Sandström, D.; Edén, M.; Bovee-Geurts, P.; ... ; Levitt, M.H.

\section{Citation}

Feng, X., Verdegem, P. J. E., Lee, Y. K., Sandström, D., Edén, M., Bovee-Geurts, P., ... Levitt, M. H. (1997). Direct determination of a molecular torsional angle in the membrane protein rhodopsin by solid-state NMR. Journal Of The American Chemical Society, 119(29), 6853-6857. doi:10.1021/ja970710d

Version: $\quad$ Publisher's Version

License: $\quad$ Licensed under Article 25fa Copyright Act/Law (Amendment Taverne)

Downloaded from: https://hdl.handle.net/1887/3239471

Note: To cite this publication please use the final published version (if applicable). 


\title{
Direct Determination of a Molecular Torsional Angle in the Membrane Protein Rhodopsin by Solid-State NMR
}

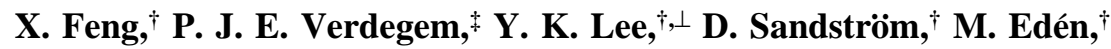 \\ P. Bovee-Geurts, ${ }^{\S}$ W. J. de Grip, ${ }^{\S}$ J. Lugtenburg, ${ }^{\ddagger}$ H. J. M. de Groot, ${ }^{\ddagger}$ and \\ M. H. Levitt $*,+$
}

Contribution from the Physical Chemistry Division, Arrhenius Laboratory, Stockholm University, S-10691 Sweden, Leiden Institute of Chemistry, Gorlaeus Laboratories, Leiden University, P.O. Box 9502, NL 2300 RA Leiden, The Netherlands, and Department of Biochemistry, Institute of Cellular Signalling, University of Nijmegen, P.O. Box 9101, NL 6500 HB Nijmegen, The Netherlands

Received March 5, 1997. Revised Manuscript Received May 6, $1997^{\otimes}$

\begin{abstract}
A solid-state NMR method (double-quantum heteronuclear local field NMR) is applied to a ${ }^{13} \mathrm{C}_{2}$ labeled sample of the $41 \mathrm{kD}$ integral membrane protein rhodopsin. The technique operates under magic-angle-spinning conditions, with good sensitivity and resolution, and allows a direct determination of molecular torsional angles, without estimating internuclear distances. In rhodopsin, we determine the $\mathrm{H}-\mathrm{C} 10-\mathrm{C} 11-\mathrm{H}$ torsional angle of the retinylidene chromophore to be $160 \pm 10^{\circ}$, indicating a significant deviation from the planar 10-11-s-trans conformation. Double-quantum heteronuclear local field NMR is shown to be a feasible method for the accurate determination of local molecular conformation in large molecular systems which are unsuitable for crystallography.
\end{abstract}

\section{Introduction}

Our understanding of structure-function relationships in biological systems is hampered by the limitations of the principal methods for examining molecular structure, namely diffraction techniques and solution nuclear magnetic resonance (NMR). Diffraction methods, such as X-ray crystallography, are restricted to systems which build well-formed three- or twodimensional crystals. The production of suitable crystals has proved very difficult for a large number of important systems, especially membrane proteins. Solution NMR, on the other hand, is feasible only for low molecular mass molecules which dissolve without aggregation. Furthermore, both methods must usually be combined with molecular modeling in order to obtain a high-resolution structure. Even the most successful studies encounter difficulties in resolving fine details of molecular structure, such as individual bond conformations. ${ }^{1}$

Solid-State NMR, especially when combined with isotopic labeling, is capable of extracting direct molecular structural information and may be applied to systems which are unsuitable for diffraction or solution NMR. Broadly speaking, these methods belong to one of three types: (i) methods which determine the orientation of a spin interaction tensor with respect to some macroscopic order axis; ${ }^{2-5}$ (ii) methods which estimate the distances between nuclear spins by measuring the magnitude

\footnotetext{
* Correspondence should be addressed to M.H.L. (mhl@physc.su.se).

$\dagger$ Stockholm University.

$¥$ Leiden University.

$\S$ University of Nijmegen.

${ }^{\perp}$ Present address: Quantum Magnetics, 740 Kenamar Court, San Diego CA 92121.

${ }^{\otimes}$ Abstract published in Advance ACS Abstracts, July 1, 1997.

(1) Ermler, U.; Fritzsch, G.; Buchanan, S. K.; Michel, H. Structure 1994, 2, 925-936.

(2) Ulrich, A. S.; Wallat, I.; Heyn, M. P.; Watts, A. Nature Struct. Biol. 1995, 2, 190-192.

(3) Tycko, R.; Stewart, P. L.; Opella, S. J. Am. Chem. Soc. 1986, 90, 5419-5425.

(4) Ketchem, R. R.; Hu, W.; Cross, T. A. Science 1993, 261, 1457-
} 1460.

(5) Tang, P.; Juang, C. L.; Harbison, G. S. Science 1990, 249, 70-72. of the spin-spin interactions ${ }^{6-10}$ and (iii) methods which directly investigate molecular geometry by determining the relative orientation of pairs of nuclear spin interactions. ${ }^{11-15}$ Type (i) methods require the preparation of a sample possessing macroscopic orientational order, while methods of type (ii) and (iii) may be applied to powders and amorphous solids.

The internuclear distance measurements involved in methods of type (ii) have been applied successfully to several biologically-interesting systems ${ }^{6-10}$ However, distance measurements are generally most useful for defining rather large-scale structural features. The accuracy is usually insufficient to define individual structural parameters such as the torsional angle about a single chemical bond. Type (iii) methods exploit correlations between pairs of tensorial nuclear spin interactions to directly access the molecular torsional angles. ${ }^{11-15}$ However, such methods have so far been applied only to small model compounds.

Recently, some of us demonstrated a new solid-state NMR method for estimating the torsional angle about a ${ }^{13} \mathrm{C}_{2}$-labeled

(6) Holl, S. M.; Marshall, G. R.; Beusen, D. D.; Kociolek, K.; Redlinski, A. S.; Leplawy, M. T.; McKay, R. A.; Vega, S.; Schaefer, J. J. Am. Chem. Soc. 1992, 114, 4830-4833.

(7) Raleigh, D. P.; Levitt, M. H.; Griffin, R. G. Chem. Phys. Lett. 1988, $146,71-76$

(8) Levitt, M. H.; Raleigh, D. P.; Creuzet, F.; Griffin, R. G. J. Chem. Phys. 1990, 92, 6347-6364.

(9) Creuzet, F.; McDermott, A.; Gebhard, R.; van der Hoef, K.; SpijkerAssink, M. B.; Herzfeld, J.; Lugtenburg, J.; Levitt, M. H.; Griffin, R. G. Science 1991, 251, 783-786.

(10) Lansbury, P. T.; Costa, P. R.; Griffiths, J. M.; Simon, E. J.; Auger, M.; Halverson, K. J.; Kocisko, D. A.; Hendsch, Z. S.; Ashburn, T. T.; Spencer, R. G. S.; Tidor, B.; Griffin, R. G. Nature Struct. Biol. 1995, 2, 990-997.

(11) Weliky, D. P.; Tycko, R. J. Am. Chem. Soc. 1996, 118, 84878488 .

(12) Schmidt-Rohr, K. J. Am. Chem. Soc. 1996, 118, 7601-7603.

(13) McDermott, A. E.; Creuzet, F.; Gebhard, R.; van der Hoef, K.; Levitt, M. H.; Herzfeld, J.; Lugtenburg, J.; Griffin, R. G. Biochemistry 1994, 33,6129 .

(14) Ishii, Y.; Terao, T.; Kainosho, M. Chem. Phys. Lett. 1996, 256, $133-140$.

(15) Feng, X.; Lee, Y. K.; Sandström, D.; Edén, M.; Maisel, H.; Sebald, A.; Levitt, M. H. Chem. Phys. Lett. 1996, 257, 314-320. 
$\mathrm{H}-\mathrm{C}-\mathrm{C}-\mathrm{H}$ molecular fragment. ${ }^{15}$ The method is called double-quantum heteronuclear local field spectroscopy (2QHLF) and is based on the excitation of double-quantum coherences between neighboring ${ }^{13} \mathrm{C}$ isotopic nuclear spin labels. Double-quantum coherence is a quantum state of correlated transverse spin polarizations. By allowing this correlated quantum state to evolve in the presence of local fields from the bonded ${ }^{1} \mathrm{H}$ spins, it is possible to probe the correlations in these local fields and thereby the geometrical relationship of the bonded protons to the ${ }^{13} \mathrm{C}$ pair. By experiments on ${ }^{13} \mathrm{C}_{2}$-labeled polycrystalline model compounds, it was possible to measure $\mathrm{H}-\mathrm{C}-\mathrm{C}-\mathrm{H}$ torsional angles with accuracies of $\sim \pm 20^{\circ}$ in the neighborhood of the cis conformation and $\sim \pm 10^{\circ}$ in the neighborhood of the trans conformation.

The 2Q-HLF experiment has a number of features which makes it highly suitable for studying the conformations of individual molecular bonds in biomolecules: (i) the experiment has high sensitivity and resolution, since it operates under magicangle-spinning conditions-recent advances allow doublequantum experiments to be performed with good sensitivity; ${ }^{16}$ (ii) the torsional angle estimation does not require assumptions as to the orientations of chemical shift anisotropy tensors, which otherwise degrade the reliability of the method; (iii) the use of double-quantum coherence suppresses the disturbing signals from randomly-distributed natural ${ }^{13} \mathrm{C}$ spins, since doublequantum coherence cannot be supported by systems of less than two coupled spins-1/2. ${ }^{17}$ In this report, the 2 Q-HLF method is applied to determining a molecular torsional angle in the visual protein rhodopsin, with a molecular mass of $\sim 41 \mathrm{kD}$.

Rhodopsin is the light receptor protein responsible for the primary visual response in vertebrate rod cells. It is a membrane-spanning seven-helix G-coupled protein, with the 11cis-retinylidene chromophore bound to the lysine-296 residue by a protonated Schiff base linkage (Figure 1a). Since good crystals have not yet been obtained, there is no high-resolution X-ray structural data. The current knowledge of the structure of rhodopsin is based on electron diffraction projection maps in combination with homology modeling, ${ }^{18,19}$ spectroscopic evidence, and the behavior of chemical modifications and mutants. ${ }^{20}$

Solid-state NMR has already played a significant role in the study of retinal proteins. For example, it was firmly established by rotational resonance NMR that the chromophore in the related system bacteriorhodopsin adopts a 6-s-trans conformation, unlike vertebrate rhodopsin, which is 6-s-cis. ${ }^{9}$ Smith and coworkers studied ${ }^{13} \mathrm{C}$ isotropic chemical shifts in bovine rhodopsin and several photointermediates. ${ }^{21,22}$ They were able to build up a picture of the geometry of the chromophore with respect to its binding pocket, both in rhodopsin and the primary photoproduct, bathorhodopsin, which has a formal 11-trans configuration instead of 11-cis. ${ }^{22}$

Recently, much attention has been focused on the mechanism for the extremely fast (200 fs) photoisomerization process. ${ }^{23} \mathrm{It}$

(16) Lee, Y. K.; Kurur, N. D.; Helmle, M.; Johannessen, O. G.; Nielsen, N. C.; Levitt, M. H. Chem. Phys. Lett. 1995, 242, 304-309.

(17) Tycko, R.; Dabbagh, G. J. Am. Chem. Soc. 1991, 113, 9444.

(18) Schertler, G. F. X.; Villa, C.; Henderson, R. Nature 1993, 362, 770772.

(19) Baldwin, J. M. EMBO J. 1993, 12, 1693-1703.

(20) Birge, R. R. Biochem. Biophys. Acta 1990, 1016, 293-327.

(21) Smith, S. O.; Courtin, J.; de Groot, H.; Gebhard, R.; Lugtenburg, J. Biochemistry 1991, 30, 7409-7415.

(22) Han, M.; Smith, S. O. Biochemistry 1995, 34, 1425-1432. The $\mathrm{C} 11-\mathrm{C} 12-\mathrm{C} 13-\mathrm{C} 14$ torsion angle was given with an incorrect sign in this publication (Smith, S. O., private communication, erratum to be published).

(23) Schoenlein, R. W.; Peteanu, L. A.; Mathies, R. A.; Shank, C. V. Science 1991, 254, 412-415. a

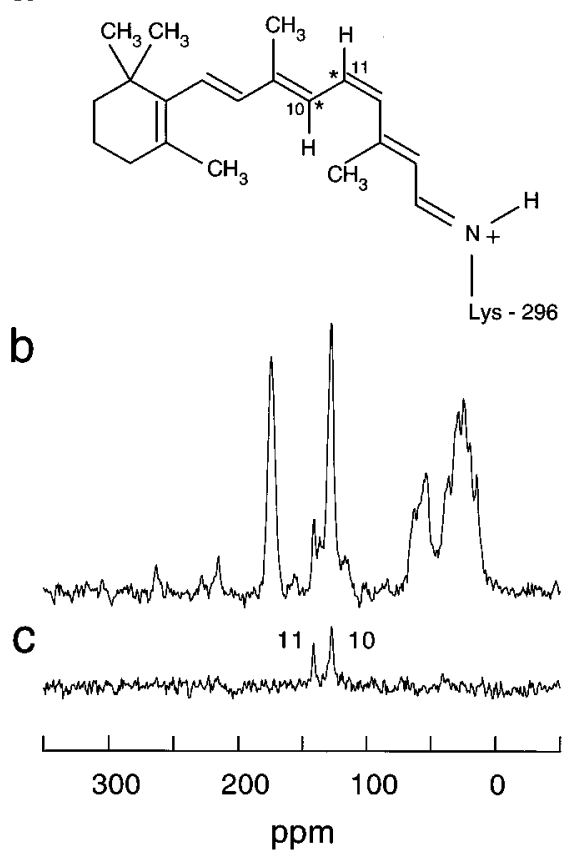

Figure 1. (a) Molecular structure of the retinylidene chromophore in rhodopsin. The ${ }^{13} \mathrm{C}$ labels are indicated by an asterisk. (b) Crosspolarization magic-angle-spinning ${ }^{13} \mathrm{C}$ NMR spectra of membranebound bovine rhodopsin. (c) Spectrum obtained by ${ }^{13} \mathrm{C}_{2}$ doublequantum filtration using the $\mathrm{C} 7$ pulse sequence. The signals from the ${ }^{13} \mathrm{C}_{2}$-labeled retinal chromophore are selected, while the natural abundance background signals are suppressed.

has been postulated that a steric interaction between the proton attached to $\mathrm{C} 10$ and the $\mathrm{C} 20$ methyl group causes a deviation from planar geometry in the $\mathrm{C} 11=\mathrm{C} 12$ region of the chromophore, accelerating the isomerization. ${ }^{24}$ In line with this conjecture, 9-cis-rhodopsin, which lacks these steric interactions, isomerizes more slowly than the natural 11-cis isomer. ${ }^{24}$

The model of the rhodopsin ground state proposed by Han and Smith ${ }^{22}$ involves a C11-C12-C13-C14 torsional angle of $\sim-140^{\circ}$, while a planar geometry is maintained around the $\mathrm{C} 10-\mathrm{C} 11$ single bond. However, recent $a b$ initio molecular dynamics simulation $\mathrm{s}^{25}$ suggest that the twist is shared between the $\mathrm{C} 10-\mathrm{C} 11$ and $\mathrm{C} 12-\mathrm{C} 13$ single bonds. These $\mathrm{Car}-$ Parrinello calculations predict that the $\mathrm{H}-\mathrm{C} 10-\mathrm{C} 11-\mathrm{H}$ torsional angle is $\sim-165^{\circ}$ in the rhodopsin ground state. In this article, independent experimental evidence is given for a $\mathrm{H}-\mathrm{C} 10-\mathrm{C} 11-\mathrm{H}$ torsional angle of $\sim-160^{\circ}$.

\section{Experimental Section}

Sample Preparation. The $11-c i s-\left[10,11-{ }^{13} \mathrm{C}_{2}\right]-$ retinal was synthesized using a previously reported procedure, ${ }^{26}$ starting from commercially available ${ }^{13} \mathrm{C}_{2}$-acetonitrile (Cambridge Isotope Laboratories, MA). all-trans-[10,11-13 $\left.\mathrm{C}_{2}\right]$ Retinal was obtained by purification of the retinal isomer mixture using silica gel column chromatography. The all-trans-retinal was subsequently irradiated in dry acetonitrile and in a dry nitrogen atmosphere for $16 \mathrm{~h}$ using a $100 \mathrm{~W}$ incandescent lamp. The $11-c i s-\left[10,11-{ }^{13} \mathrm{C}_{2}\right]$ retinal was isolated from the photostationary mixture with preparative HPLC, using a Zorbax silica gel column 21.2 $\mathrm{mm} \times 25 \mathrm{~cm}$ (Du Pont, Delaware). The purity of the labeled retinal was confirmed with $300 \mathrm{MHz}{ }^{1} \mathrm{H} \mathrm{NMR}\left(\mathrm{CDCl}_{3}\right), 75.4 \mathrm{MHz}{ }^{1} \mathrm{H}$ noise decoupled ${ }^{13} \mathrm{C}$ NMR $\left(\mathrm{CDCl}_{3}\right)$, and mass spectrometry. The incorporation was better than $90 \%$ for every individual label.

(24) Schoenlein, R. W.; Peteanu, L. A.; Wang, Q.; Mathies, R. A.; Shank, C. V. J. Phys. Chem. 1993, 97, 12087-12092.

(25) Bifone, A.; de Groot, H. J. M.; Buda, F. J. Phys. Chem. 1996, in press.

(26) Groesbeek, M.; Lugtenburg, J. Photochem. Photobiol. 1992, 56, 903-908. 


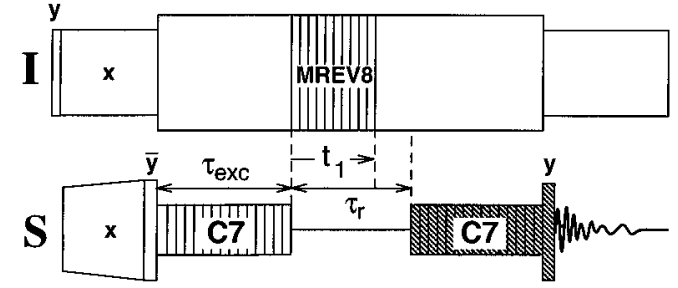

Figure 2. Pulse sequence for determination of $\mathrm{H}-\mathrm{C}-\mathrm{C}-\mathrm{H}$ torsional angles under magic-angle spinning conditions, through heteronuclear dipolar modulation of the double-quantum coherences. The pulse sequence requires that the $\mathrm{rf}$ carrier is set to the mean of the ${ }^{13} \mathrm{C}$ isotropic shift frequencies. The homonuclear recoupling sequence $\mathrm{C} 7$ is described in ref 16.

All manipulations with the pure cis isomer and rhodopsin were performed in dim red light $(\lambda>700 \mathrm{~nm})$ or in the dark. Approximately 40 bovine retinas from fresh cow eyes were used to obtain membrane fragments containing rhodopsin, which were reconstituted using published procedures..$^{27}$ A 2-fold excess of the labeled retinal was used to obtain optimal incorporation. The remaining free retinal was removed by washing the membrane fragment suspension with $50 \mathrm{mM}$ $\beta$-cyclodextrine solution, until absorbance in the supernatant due to the retinal was no longer observed. The regeneration was determined by comparing the $A_{280} / A_{500}$ ratio with that of native rhodopsin and was better than $90 \%$. The NMR sample $(15 \mathrm{mg})$ was concentrated in the dark and loaded into a $4 \mathrm{~mm}$ zirconiumoxide rotor sealed with a boronitride cap. The NMR sample contained $\sim 0.5 \mu M$ of ${ }^{13} \mathrm{C}_{2}$-labeled rhodopsin.

2Q-HLF Experiment. The 2Q-HLF experiment employs a radiofrequency (rf) pulse sequence, appropriate for organic solids containing ${ }^{13} \mathrm{C}_{2}$ spin pairs, as shown in Figure 2. Rf fields at the Larmor frequency of the ${ }^{1} \mathrm{H}$ and ${ }^{13} \mathrm{C}$ spins are denoted $I$ and $S$, respectively.

The experiment starts by cross-polarization (CP) for enhancing the transverse ${ }^{13} \mathrm{C}$ magnetization. During $\mathrm{CP}$, a slight ramp of the ${ }^{13} \mathrm{C} \mathrm{rf}$ field is employed to improve reproducibility. ${ }^{28}$ After CP, the transverse ${ }^{13} \mathrm{C}$ magnetization is rotated to the $z$-axis by a $\pi / 2$ pulse of appropriate phase.

The $z$-magnetization of the ${ }^{13} \mathrm{C}_{2}$ pairs is converted into doublequantum coherence (2QC) by the $\mathrm{C} 7$ pulse scheme. ${ }^{16}$ Briefly, C7 consists of a repetitive series of rf pulse cycles, each shifted in phase by $2 \pi / 7$ radians with respect to the preceding cycle. Each rf cycle consists of two pulses of flip angle $2 \pi$, with phases differing by $\pi$. The duration of each cycle is timed so as to occupy $2 / 7$ of a rotational period. The complete sequence of seven rf phase shifts is therefore completed every second revolution of the sample. As shown in ref 16 , this arrangement ensures efficient double-quantum excitation in coupled spin-1/2 pairs. Typically, ${ }^{13} \mathrm{C}$ signals are passed through double-quantum coherence with about $50 \%$ efficiency. This high efficiency is essential for biological applications.

The ${ }^{13} \mathrm{C}$ double-quantum coherences are allowed to evolve for an interval $\tau_{r}$, the sample rotational period. This constant interval is divided into two portions: The first part is a variable interval $t_{1}$, occupied by a homonuclear decoupling pulse sequence, applied on the proton channel. Homonuclear ${ }^{1} \mathrm{H}-1{ }^{-} \mathrm{H}$ couplings are effectively suppressed, leaving heteronuclear ${ }^{1} \mathrm{H}-{ }^{13} \mathrm{C}$ interactions scaled down by the factor $\kappa<1 .{ }^{29}$ In the experiments, semiwindowless MREV $8^{30}$ was used. The MREV8 sequence temporarily "freezes" the polarizations of the attached protons, allowing the ${ }^{13} \mathrm{C}_{2}$ double-quantum precession to probe the geometrical relationship of the $\mathrm{C}-\mathrm{H}$ magnetic couplings. The second part consists of an interval $\tau_{r}-t_{1}$, occupied by unmodulated high-power proton decoupling. During this period, all ${ }^{1} \mathrm{H}-{ }^{13} \mathrm{C}$ couplings are suppressed. A set of experiments is conducted in which the first interval $t_{1}$ is increased, and the second interval $\tau_{r}-t_{1}$ contracted,

(27) De Grip, W. J.; Daeman, F. J. M.; Bonting, S. L. Methods in Enzymology Academic Press: New York, 1980; Vol. 67.

(28) Metz, G.; Wu, X.; Smith, S. O. J. Magn. Reson. 1994, A110, 219227.

(29) Stoll, M. E.; Rhim, W.-K.; Vaughan, R. W. J. Chem. Phys. 1976, $64,4808-4809$.

(30) Rhim, W. K.; Elleman, D. D.; Vaughan, R. W. J. Chem. Phys. 1973, $59,3740-3749$. keeping the total interval fixed and equal to one rotor period $\tau_{r}$. This removes the effect of ${ }^{13} \mathrm{C}$ shift anisotropies on the double-quantum evolution. The effect of the ${ }^{13} \mathrm{C}$ isotropic shift is removed by setting the spectrometer carrier frequency to the mean isotropic shift frequency of the two sites.

The modulated double-quantum coherences are reconverted into $z$-magnetization by a second $\mathrm{C} 7$ sequence, of the same duration as the first. This $z$-magnetization is converted by a $\pi / 2$ pulse into observable signal. A standard procedure for selection of signals passing through 2QC is applied. ${ }^{31}$ In a large molecule, double-quantum filtering has the important feature of suppressing the signals from randomlydistributed natural ${ }^{13} \mathrm{C}$ spins.

The experiments were performed on a modified Bruker MSL200 spectrometer at a magnetic field of $4.7 \mathrm{~T}$. A standard $4 \mathrm{~mm}$ Bruker double-resonance probe was used. A temperature of $230 \mathrm{~K}$ was used to immobilize the rhodopsin in the lipid matrix. The experiments were conducted at a moderate sample rotational frequency of $\left|\omega_{r} / 2 \pi\right|=4430$ $\mathrm{Hz}$. The rf magnetic flux density at the ${ }^{13} \mathrm{C}$ Larmor frequency corresponded to a nutation frequency of $\left|\omega_{\text {nut }}^{\mathrm{S}} / 2 \pi\right|=31.0 \mathrm{kHz}$. The rf magnetic flux density at the ${ }^{1} \mathrm{H}$ Larmor frequency was switched between three levels: The proton nutation frequency $\left|\omega_{\text {nut }}^{\mathrm{I}} / 2 \pi\right|$ was $56.8 \mathrm{kHz}$ during cross-polarization, $76.2 \mathrm{kHz}$ during the $\mathrm{C} 7$ and MREV8 sequences, and $66.5 \mathrm{kHz}$ during ${ }^{13} \mathrm{C}$ signal acquisition. A crosspolarization time of $2.0 \mathrm{~ms}$ was used. The double-quantum excitation interval was $\tau_{\mathrm{exc}}=452 \mu \mathrm{s}$. Both $\mathrm{C} 7$ excitation and reconversion sequences contained seven cycles. The ${ }^{13} \mathrm{C}$ rf carrier frequency was set to the mean of the isotropic absolute Larmor frequencies of the two labeled sites in all-trans-[10,11- $\left.{ }^{13} \mathrm{C}_{2}\right]$-retinal. The MREV8 cycle period $\tau_{\mathrm{MREV}}$ was set to the harmonic condition $\tau_{\mathrm{MREV}}=\tau_{r} / 8$. The interval $t_{1}$ was increased from 0 to $\tau_{r}$ in steps of $\tau_{\mathrm{MREV}} / 2$, comprising 17 different experiments in all. The data for all-trans- $\left[10,11-{ }^{13} \mathrm{C}_{2}\right]-$ retinal were collected under identical experimental conditions.

\section{Results and Discussion}

Double-Quantum Magic-Angle Spinning NMR of Rhodopsin. Figure $1 \mathrm{~b}$ shows the magic-angle-spinning ${ }^{13} \mathrm{C}$ spectrum of the labeled rhodopsin in the dark. This spectrum is the result of 160 min of signal acquisition, during which 2400 signal transients were collected. A common problem of biomolecular solid-state NMR is evident: The interesting signals from the ${ }^{13} \mathrm{C}$ labels are largely obscured by signals from randomlydistributed natural ${ }^{13} \mathrm{C}$ spins in the protein and lipid membrane.

The natural abundance background is eliminated by using C7 to pass the NMR signals through ${ }^{13} \mathrm{C}_{2}$ double-quantum coherence, as shown in Figure 1c. Apart from the use of doublequantum filtering, the experimental conditions, including the number of acquired transients, and total signal acquisition time were the same as in Figure 1b. The two peaks in Figure 1c are assigned to the $10-{ }^{13} \mathrm{C}$ site (right-hand peak) and $11-{ }^{13} \mathrm{C}$ site (left-hand peak) of protein-bound protonated Schiff base retinal, as is verified by their isotropic chemical shift difference of 14.2 ppm. ${ }^{21}$ The asymmetry in the peak intensities is due to an interplay of ${ }^{13} \mathrm{C}-{ }^{13} \mathrm{C}$ spin-spin couplings and chemical shift anisotropies. This has been verified by numerical simulations using the procedure described in ref 8 .

Estimation of the $\mathrm{H}-\mathrm{C10}-\mathrm{C11}-\mathrm{H}$ Torsional Angle. To measure the $\mathrm{H}-\mathrm{C}-\mathrm{C}-\mathrm{H}$ torsional angle, a set of experimental double-quantum-filtered signal amplitudes $a_{\exp }\left(t_{1}\right)$ is gathered as a function of the double-quantum evolution interval $t_{1}$. The $\mathrm{H}-\mathrm{C}-\mathrm{C}-\mathrm{H}$ torsional angle is estimated by matching the experimental amplitudes $a_{\exp }\left(t_{1}\right)$ to theoretical curves of the form

$$
a\left(t_{1}\right)=A f\left(t_{1}, \kappa, \mathbf{G}\right) \exp \left\{-\lambda t_{1}\right\}
$$

Here $A$ sets the experimental vertical scale. The function $f$

(31) Ernst, R. R.; Bodenhausen, G.; Wokaun, A. Principles of Nuclear Magnetic Resonance in One and Two Dimensions; Clarendon Press: Oxford, 1987. 
depends on the evolution period $t_{1}$ and the set of geometrical parameters $\mathbf{G}$ characterizing the positions of the atoms in the local $\mathrm{H}-\mathrm{C}-\mathrm{C}-\mathrm{H}$ fragment. These geometrical parameters include the $\mathrm{C}-\mathrm{H}$ bond length $r_{\mathrm{CH}}$, the $\mathrm{C}-\mathrm{C}$ bond length $r_{\mathrm{CC}}$, the $\mathrm{H}-\mathrm{C}-\mathrm{C}$ bond angles $\theta_{\mathrm{HCC}}^{(1)}$ and $\theta_{\mathrm{HCC}}^{(2)}$, and the $\mathrm{H}-\mathrm{C}-\mathrm{C}-\mathrm{H}$ torsional angle, which will be denoted $\phi$. Since the experiment is insensitive to the absolute sign of the torsional angle, the symbol $|\phi|$ is used in the following discussion. The function $f$ also depends on the scaling factor $\kappa$ of the multipulse sequence, which indicates the reduction of the effective ${ }^{13} \mathrm{C}-{ }^{1} \mathrm{H}$ couplings associated with the ${ }^{1} \mathrm{H}$ irradiation. $f$ may readily be calculated numerically for any desired molecular geometry. ${ }^{15}$ Note that $f$ displays no dependence on isotropic or anisotropic chemical shifts. Furthermore, $f$ does not depend on the relaxation parameters of the spin system. Since each ${ }^{1} \mathrm{H}-{ }^{13} \mathrm{C}-{ }^{13} \mathrm{C}-{ }^{1} \mathrm{H}$ spin system may be regarded as essentially isolated over the single rotor period of double-quantum evolution, the ${ }^{13} \mathrm{C}_{2}$ double-quantum coherence is expected to relax with a simple exponential decay under the ${ }^{1} \mathrm{H}$ multiple-pulse sequence. This decay is taken into account by a phenomenological damping time constant $\lambda$. This relaxation model is admittedly crude, but the precise form of the double-quantum relaxation is not critical for the interpretation of the results. In practice, $\lambda$ and $A$ are determined by least-square fits of $a\left(t_{1}\right)$ to the experimental set of amplitudes $a_{\exp }\left(t_{1}\right)$.

There are two obstacles to the extraction of the torsional angle $|\phi|$ from the experimental set of amplitudes $a_{\exp }\left(t_{1}\right)$. Firstly, the scaling factor for the multiple-pulse sequence $\kappa$ is not generally known for the actual experimental conditions. Secondly, the geometrical parameters $r_{\mathrm{CH}}, r_{\mathrm{CC}}, \theta_{\mathrm{HCC}}^{(1)}$, and $\theta_{\mathrm{HCC}}^{(2)}$ are uncertain for the molecule under study. The $\mathrm{C}-\mathrm{H}$ bond length $r_{\mathrm{CH}}$ poses particular problems: The dipolar interactions are subject to vibrational averaging, leading to effective bond lengths which deviate substantially from the bond lengths estimated by diffraction measurements. In the simulations, we used an effective $\mathrm{C}-\mathrm{H}$ bond length $r_{\mathrm{CH}}=0.113 \mathrm{~nm}$, as given in ref 32. Note, however, that the simulations are sensitive (within a broad range) only to the value of the product $\kappa r_{\mathrm{CH}}^{-3}$, since the spin dynamics are dominated by the nearest-neighbor interactions between each ${ }^{13} \mathrm{C}$ and its directly-bonded proton. The analysis does not therefore require an accurate estimate of the individual parameters $r_{\mathrm{CH}}$ and $\kappa$. An estimate of the product $\kappa r_{\mathrm{CH}}^{-3}$ is sufficient.

We used a polycrystalline sample of all-trans-[10,11- $\left.{ }^{13} \mathrm{C}_{2}\right]-$ retinal for calibration. The $\mathrm{H}-\mathrm{C}-\mathrm{C}-\mathrm{H}$ torsional angle about the 10,11 bond in this compound is known to be very close to $180^{\circ}$ from X-ray crystallography. ${ }^{33}$ The experimental amplitudes $a_{\text {exp }}\left(t_{1}\right)$ are shown by the filled circles in Figure 3 . These points show a strong damping as a function of $t_{1}$. This damping is not observed for retinal at room temperature or for the compounds studied in ref 15 at any temperature. It may be associated with a particular motional process in retinal. In any case, it does not significantly disturb the torsional angle measurement.

The solid line in Figure 3 corresponds to the theoretical $a\left(t_{1}\right)$ curve for the known geometrical parameters $r_{\mathrm{CC}}=0.141 \mathrm{~nm}$, $r_{\mathrm{CH}}=0.113 \mathrm{~nm}, \theta_{\mathrm{HCC}}^{(1)}=\theta_{\mathrm{HCC}}^{(2)}=115^{\circ}$, and $\phi=180^{\circ} .33$ The best fit between simulation and experiment was obtained by global minimization of the root-mean-square deviation as a function of the unknown parameters $A, \lambda$, and $\kappa$. The multiplepulse scaling factor was estimated to be $\kappa=0.50$. The

(32) Nakai, T.; Ashida, J.; Terao, T. Mol. Phys. 1989, 67, 839-847.

(33) Hamanaka, T.; Mitsui, T.; Ashida, T.; Kakudo, M. Acta Crystallogr. 1972, B28, 214-222.

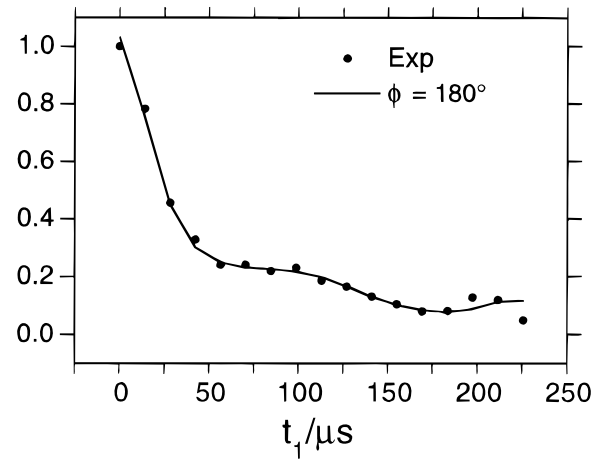

Figure 3. Signal amplitudes for $10,11-{ }^{13} \mathrm{C}_{2}$-all-trans-retinal in a doublequantum heteronuclear local field experiment. Filled circles: Experimental integrated amplitudes as a function of the evolution interval $t_{1}$. Solid line: Simulation for a $\mathrm{H}-\mathrm{C}-\mathrm{C}-\mathrm{H}$ torsional angle of $|\phi|=180^{\circ}$, $\mathrm{H}-\mathrm{C}-\mathrm{C}$ bond angles of $\theta_{\mathrm{HCC}}^{(1)}=\theta_{\mathrm{HCC}}^{(2)}=115^{\circ}$, a CH bond length of $r_{\mathrm{CH}}=0.113 \mathrm{~nm}$, a CC bond length of $r_{\mathrm{CC}}=0.141 \mathrm{~nm}$, a multiplepulse scaling factor of $\kappa=0.50$, and a damping rate constant of $\lambda=$ $9670 \mathrm{~s}^{-1}$.

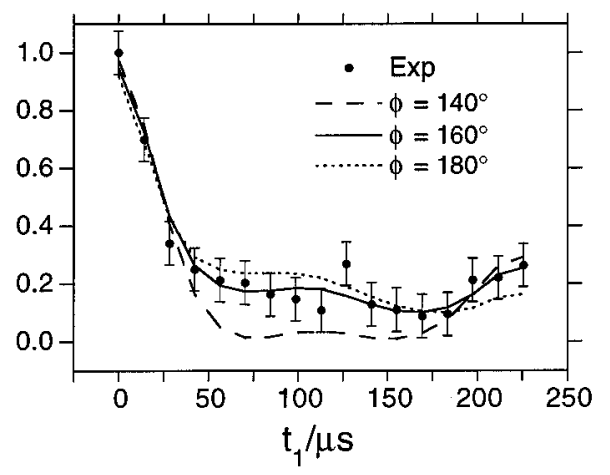

Figure 4. Signal amplitudes for $10,11-{ }^{13} \mathrm{C}_{2}$-rhodopsin in a doublequantum heteronuclear local field experiment. Filled circles: Experimental integrated amplitudes as a function of the evolution interval $t_{1}$. The error bars indicate the standard deviation of the noise. Solid line: Simulation for a $\mathrm{H}-\mathrm{C}-\mathrm{C}-\mathrm{H}$ torsional angle of $|\phi|=160^{\circ}$ and damping rate constant $\lambda=5820 \mathrm{~s}^{-1}$. Broken lines: Best fit simulations for $\mathrm{H}-\mathrm{C}-\mathrm{C}-\mathrm{H}$ torsional angle of $|\phi|=180^{\circ}$ and $|\phi|=140^{\circ}$. The damping rate constants are $\lambda=7680$ and $5340 \mathrm{~s}^{-1}$, respectively.

calibrated value of $\kappa$ was found to be almost temperatureindependent, unlike the damping rate constant $\lambda$, which was found to increase strongly with decreasing temperature. At 230 $\mathrm{K}$, the damping rate constant for all-trans-retinal is $\lambda=9670$ $\mathrm{s}^{-1}$.

The results for the labeled rhodopsin sample, performed under identical experimental conditions, are shown in Figure 4. These data are the result of around 4 days of signal acquisition. The experimental amplitudes, shown by filled circles, are integrals over the spectra multiplied by a matched weighting function, to minimize the noise contributions in the amplitude determination. The error bars represent standard deviations of the noise, estimated by performing many identical amplitude estimations on signal-free spectral regions, followed by a statistical analysis. The diagram also shows simulated curves for three different torsional angles $|\phi|$. In each case, the value $\kappa=0.50$ was retained, but the free parameters $A$ and $\lambda$ were varied so as to minimize the mean square deviation between simulation and experiment. Best fit to the experiment is obtained for the torsional angle $|\phi|=160^{\circ}$ and the damping rate constant $\lambda=$ $5820 \mathrm{~s}^{-1}$. There is a noticeable discrepancy with the simulation for exact s-trans geometry $\left(|\phi|=180^{\circ}\right)$, even when the $A$ and $\lambda$ values are adjusted for the best fit. A larger twist angle of $|\phi|=140^{\circ}$ is very clearly in disagreement with experiment. 
The experimental measurements were repeatable within the confidence limits of the thermal noise.

There are several major contributions to the uncertainties of this torsional angle estimation: (i) thermal noise contributions as well as possible systematic errors in the NMR signals; (ii) the uncertainty in the calibrated value of $\kappa$; (iii) the uncertainties in the geometric parameters used, which were taken from the crystal structure of all-trans-retinal and may not be directly applicable to the rhodopsin chromophore; (iv) the influence of dipolar couplings to more distant protons. We assessed the confidence limits for the torsional angle, taking into account all of these factors. For the rhodopsin measurements, the thermal noise contributions dominate the systematic errors (except for the experimental point at $t_{1} \sim 125 \mu \mathrm{s}$, which was probably affected by momentary probe arcing). A statistical $\chi^{2}$ error analysis ${ }^{34}$ using the measured variance of the thermal noise produced the following estimation of the torsional angle: $|\phi|=160^{\circ} \pm 6^{\circ}$. This estimate was insensitive to the calibrated value of $\kappa r_{\mathrm{CH}}^{-3}$. Long-range ${ }^{1} \mathrm{H}-{ }^{13} \mathrm{C}$ couplings also have only a minor effect on the simulated curves. However, a strong influence on the simulated evolution was produced by a change in the bond angles $\theta_{\mathrm{HCC}}^{(1)}$ and $\theta_{\mathrm{HCC}}^{(2)}$ in opposite senses. The $\mathrm{X}$-ray structure of trans-retinal ${ }^{33}$ as well as the Car-Parrinello simulations indicate that the $\mathrm{H}-\mathrm{C}-\mathrm{C}$ bond angles vary by less than $6^{\circ}$ in this type of system. When all these factors are taken into account, the following estimate for the $\mathrm{H}-\mathrm{C} 10-\mathrm{C} 11-\mathrm{H}$ torsional angle in rhodopsin is obtained: $|\phi|=160^{\circ} \pm 10^{\circ}$.

The sign of $\phi$ cannot be determined by NMR alone. However, the rhodopsin model of Han and $\mathrm{Smith}^{22}$ allows a reasonable conjecture. These authors deduced a $\mathrm{C} 11-\mathrm{C} 12-$ C13-C14 torsional angle of $-140^{\circ}$ from the NMR chemical shift data and the known geometry of the chiral binding pocket. ${ }^{22}$ If this negative twist is shared by the $\mathrm{C} 10-\mathrm{C} 11$ and $\mathrm{C} 12-\mathrm{C} 13$ single bonds, as seems reasonable, then the most likely value of the $\mathrm{H}-\mathrm{C} 10-\mathrm{C} 11-\mathrm{H}$ torsional angle in rhodopsin is $\phi=$ $-160^{\circ} \pm 10^{\circ}$.

\section{Conclusions}

We have shown that double-quantum heteronuclear local field spectroscopy is a feasible method for determination of local

(34) Bevington, P. R. Data Reduction and Error Analysis in the Physical Sciences; McGraw-Hill: New York, 1969. molecular structural information in quite large biomolecular systems. The experiment proved feasible for a $41 \mathrm{kD}$ system, even at our rather low magnetic field of $4.7 \mathrm{~T}$. The $\mathrm{H}-\mathrm{C} 10-$ $\mathrm{C} 11-\mathrm{H}$ torsional angle in the rhodopsin ground state was estimated as $-160^{\circ} \pm 10^{\circ}$, in good agreement with recent $a b$ initio calculations. ${ }^{25}$ This supports the hypothesis that the photoisomerization of rhodopsin is accelerated by nonplanarity of the conjugated system in the vicinity of the $\mathrm{C} 11=\mathrm{C} 12$ double bond. The accuracy of the torsional angle determination is remarkable, in view of the fact that the sample possessed no molecular orientational order.

It should be possible to study much larger molecular systems as well as rhodopsin photointermediates, by using higher-field spectrometers. The method may be especially important for establishing the precise conformations of ligands in the active sites of proteins. The bond to be investigated is determined by the position of the introduced ${ }^{13} \mathrm{C}_{2}$ pair. Furthermore, since the method only exploits very local spin dynamics, it should be possible to work with samples labeled with several spin pairs, without excessive interference between the pairs. This will allow many bond conformations to be investigated simultaneously on a single isotopically-labeled sample. In addition, the experiment can readily be extended to estimate ${ }^{1} \mathrm{H}-{ }^{13} \mathrm{C}-$ ${ }^{15} \mathrm{~N}-{ }^{1} \mathrm{H}$ and ${ }^{15} \mathrm{~N}-{ }^{13} \mathrm{C}-{ }^{13} \mathrm{C}-{ }^{15} \mathrm{~N}$ torsional angles and thereby study chain conformations in peptides and proteins. An experiment of this kind has been reported. ${ }^{35}$ Related experiments are feasible in the solution state, where the relative orientations of pairs of internuclear vectors are revealed by studying double-quantum relaxation. ${ }^{36}$

Acknowledgment. This research was supported by the Swedish Natural Science Research Foundation, the European Union Biotechnology Program (PL 920467), and the Netherlands Foundation for Scientific Research (SON-NWO). We would like to thank Ole Johannessen, Michael Helmle, Oleg Antzutkin, Angelika Sebald, and Torgny Karlsson for help and discussions.

\section{JA970710D}

(35) Hong, M.; Gross, J.; Griffin, R. G. 38th Experimental Nuclear Magnetic Resonance Conference; Orlando, FL, 1997.

(36) Reif, B.; Hennig, M.; Griesinger, C. 38th Experimental Nuclear Magnetic Resonance Conference; Orlando, FL, 1997. 